\title{
COMPARISON OF CONVENTIONAL THYROIDECTOMY AND HORIZONTAL LATERAL INCISION THYROIDECTOMY
}

\author{
Dimmy Harold ${ }^{1}$, Abdul Latheef A2, I. J. Jinu ${ }^{3}$ \\ 1 Junior Resident, Department of General Surgery, TD Medical College, Alappuzha. \\ 2 Professor and HOD, Department of General Surgery, TD Medical College, Alappuzha. \\ ${ }^{3}$ Assistant Professor, Department of General Surgery, TD Medical College, Alappuzha.
}

\begin{tabular}{l} 
ABSTRACT \\
\hline BACKGROUND \\
Objectives- Thyroid surgery, one of the most common surgeries done by a general surgeon has evolved over the years. Surgeons \\
have strived to improve patient outcomes by evolving their surgical technique and thus reducing postoperative morbidity- \\
pathophysiological and cosmetic. This study compared conventional thyroidectomy and horizontal lateral incision thyroidectomy.
\end{tabular}

\section{MATERIALS AND METHODS}

A prospective observational study was done between January 2015 and June 2016 in patients with thyroid swelling who had undergone thyroidectomy. Patients included in the study were those with Solitary nodule thyroid and Multinodular thyroid. Forty patients from both groups are selected. After obtaining Institutional Ethics Committee clearance, the study was carried out. Written informed consents were obtained from patients. Study questionnaire was administered at the onset and during postoperative follow up. Outcome variables such as cosmetic appearance, hypocalcaemia and recurrent laryngeal nerve palsy were compared. Scar was analysed using observer scar assessment scale and patient's scar assessment scale. Scar was assessed at 4 weeks, 8 weeks and 6 months. Hypocalcaemia was assessed by serum calcium and clinical features during postoperative period. Every patient was assessed for recurrent laryngeal nerve palsy by direct laryngoscopy in immediate post-operative period. Patients who have change in voice or stridor postoperatively were further assessed by indirect laryngoscopy.

\section{RESULTS}

There is statistically significant difference between the two groups with regards to the outcome of the scar in OSAS and PSAS. The scar was significantly better in thyroidectomy done through lateral incision thyroidectomy [p value- 0.003 and $p$ value- 0.000 for OSAS and PSAS respectively]. Thus, scar in lateral incision thyroidectomy is found to be cosmetically far better compared to the conventional incision thyroidectomy.

\section{CONCLUSION}

Lateral or horizontal incision thyroidectomy is analogous and feasible alternative to conventional thyroidectomy in selected cases. The advantage of this technique is an enhanced aesthetic result. This technique is not recommended in huge thyroid, retrosternal thyroid, thyroiditis and malignancy, so it cannot be recommended as a standard therapy. Study on a large number of patients, preferably randomised double-blinded studies with longer followup periods is recommended.

\section{KEYWORDS}

Thyroidectomy, Lateral Thyroidectomy, Scar Assessment Scale, Hypocalcaemia, Recurrent Laryngeal Nerve Palsy, Cosmesis.

HOW TO CITE THIS ARTICLE: Harold D, Latheef AA, Jinu IJ. Comparison of conventional thyroidectomy and horizontal lateral incision thyroidectomy. J. Evolution Med. Dent. Sci. 2017;6(28):2286-2291, DOI: 10.14260/Jemds/2017/492

\section{BACKGROUND}

Thyroid surgery has followed all the steps of evolution to reach the time of endoscopic surgery. Thyroidectomy is one of the common surgical interventions for thyroid disease. Modern thyroid surgery owes much to one man called Theodor Kocher, Professor of Surgery at Berne, Switzerland. He can be called Father of thyroid surgery.

Financial or Other, Competing Interest: None.

Submission 27-02-2017, Peer Review 23-03-2017,

Acceptance 30-03-2017, Published 06-04-2017.

Corresponding Author:

Dr. Dimmy Harold,

Mannamkery,

South Gate P. $O$

Vaikom,

Kottayam-686141,

Kerala, India

E-mail:dimmyharold@gmail.com,drlatheef62@gmail.com

DOI: $10.14260 /$ jemds $/ 2017 / 492$

\section{(c) $(i) \Theta$}

In conventional thyroidectomy incision should be almost exactly transverse, extending well on to the borders of the sternocleidomastoid muscles (Kocher's neck collar incision), made about two fingers above the sternal notch. This millennium is of minimally invasive techniques. Patients are much more concerned about cosmesis. So surgeons are obliged to do cosmetic approach for every surgery. Horizontal incision thyroidectomy scar from $4.5 \mathrm{~cm}$ at lower crease extending from posterior (Lateral) border of sternocleidomastoid posterolaterally. Scar will be assessed at 4 weeks, 8 weeks and after 6 months.

Aims of the study are to compare the results of conventional thyroidectomy and horizontal lateral incision thyroidectomy in terms of cosmesis (Scar assessment score) and complications (hypocalcaemia, recurrent laryngeal nerve palsy).

\section{Ethical Considerations}

Study has been conducted after getting approval from Institutional Ethical Committee. A written informed consent 
has been taken from all the patients included in the study. Patients participating in the study did not have to incur any expenses. The anonymity of each individual has been maintained.

\section{MATERIALS AND METHODS}

\section{Study Design}

This is a prospective observational study.

\section{Study Period and Duration}

Study was conducted over a period of one and a half years from January 2015 to June 2016.

\section{Study Setting}

Study was conducted on patients with thyroid swelling who underwent thyroidectomy in general surgery ward, Government T. D. Medical College and Hospital, Vandanam, Kerala.

\section{Sample Size}

This study was carried out as a part of fulfilment of PG course and hence had to be completed within one and a half years. Sample was selected on the basis of number of elective thyroidectomies to be done by a particular surgical unit from January 2015 to June 2016. As there is only one theatre day per week for a unit in our department, assuming one thyroidectomy per week, the maximum number of possible cases which can be done is 40 . So, sample size was taken as 40 .

\section{Method of Allocation of Group}

Patients admitted in surgical ward in our unit are counselled about the two types of surgical methods. Those who wish to undergo the particular procedure are selected after obtaining informed consent.

\section{Group 1}

Horizontal lateral incision thyroidectomy- 40 patients.

\section{Group 2}

Conventional large incision thyroidectomy- 40 patients.

\section{Study Population \\ Inclusion Criteria}

1. Solitary nodule thyroid.

2. Multinodular thyroid.

\section{Exclusion Criteria}

1. Malignancy.

2. Large retrosternal thyroid.

3. Thyroiditis.

\section{Study Procedure}

Protocol was initiated after obtaining Institutional Ethical Committee. After getting informed consent, patients were interviewed based on an appropriate semi-structured questionnaire and they were followed up after surgery.

\section{Study Variables}

The variables studied were age of the patient, gender, diagnosis, type of incision, type of surgery, complications (Hypocalcaemia, Recurrent laryngeal nerve palsy) and scar assessment scale- OSAS (Observer Scar Assessment Scale) and PSAS (Patient Scar Assessment Scale).

\section{Data Analysis}

Statistical Method- Mann-Whitney U Test.

All the analysis was done using qualitative variables in Statistical Package for Social Sciences (SPSS) version 16.

\section{RESULTS}

1. Age

\begin{tabular}{|c|c|c|}
\hline Age & Count & Percent \\
\hline$<30$ & 10 & 12.5 \\
\hline $30-40$ & 25 & 31.3 \\
\hline $40-50$ & 30 & 37.5 \\
\hline $50-60$ & 10 & 12.5 \\
\hline$>60$ & 5 & 6.3 \\
\hline \multicolumn{3}{|c|}{ Table 1. Percentage Distribution of } \\
the Sample, According to Age \\
\hline
\end{tabular}

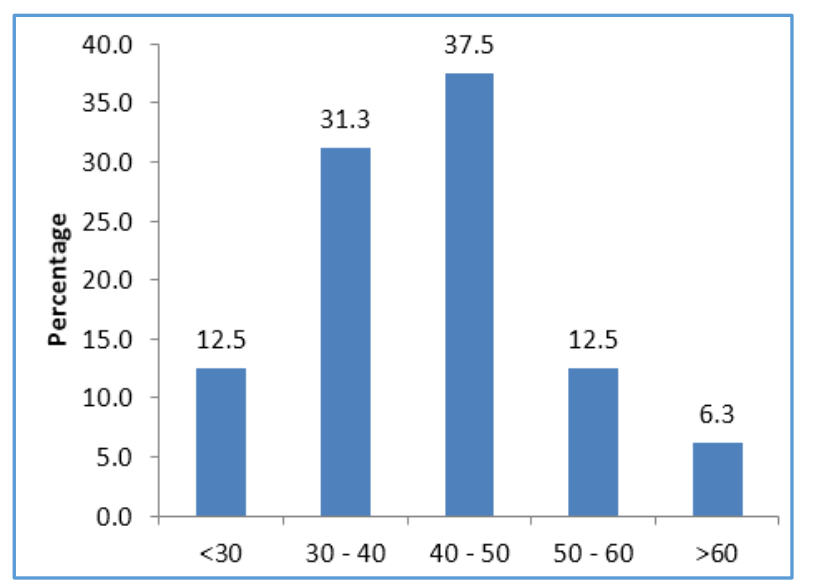

Graph 1. Percentage Distribution of the Sample, According to Age

Most of the patients in the study were in the age group 30 - 50 yrs., with that is $68.8 \%$ that is 30 patients in $40-50$ and 25 in 30 - 40 years' group.

\section{Gender}

\begin{tabular}{|c|c|c|}
\hline Gender & Count & Percent \\
\hline Male & 19 & 23.8 \\
\hline Female & 61 & 76.3 \\
\hline \multicolumn{2}{|c|}{ Table 2. Percentage Distribution } \\
of the Sample, According to Gender \\
\hline
\end{tabular}

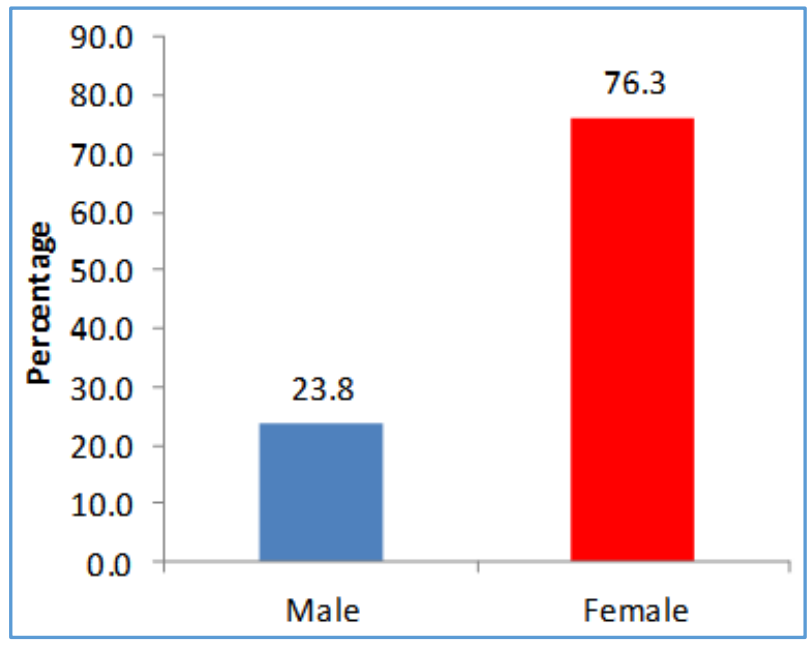

Graph 2. Percentage Distribution of the Sample, According to Gender 
In the study population, the percentage of female patients was $61 \%$ and the percentage of male was $19 \%$.

\section{Distribution of Age and Gender}

\begin{tabular}{|c|c|c|c|c|}
\hline \multirow{2}{*}{ Age } & \multicolumn{2}{|c|}{ Male } & \multicolumn{2}{c|}{ Female } \\
\cline { 2 - 5 } & Count & Percent & Count & Percent \\
\hline$<30$ & 1 & 5.3 & 9 & 14.8 \\
\hline $30-40$ & 6 & 31.6 & 19 & 31.1 \\
\hline $40-50$ & 4 & 21.1 & 26 & 42.6 \\
\hline $50-60$ & 6 & 31.6 & 4 & 6.6 \\
\hline$>60$ & 2 & 10.5 & 3 & 4.9 \\
\hline \multicolumn{6}{|c}{ Table 3. Distribution of Age and Gender } \\
\hline
\end{tabular}

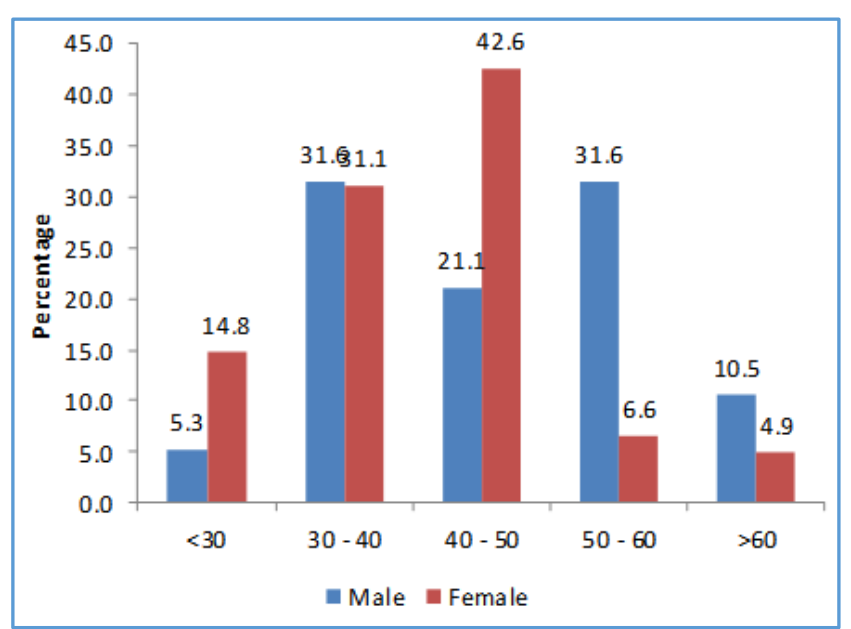

Graph 3. Distribution of Age and Gender

4. Diagnosis

\begin{tabular}{|c|c|c|}
\hline Diagnosis & Count & Percent \\
\hline Solitary nodule thyroid & 44 & 55.0 \\
\hline Multinodular thyroid & 36 & 45.0 \\
\hline \multicolumn{2}{|c|}{ Table 4. Percentage Distribution } \\
of the Sample, According to Diagnosis \\
\hline
\end{tabular}

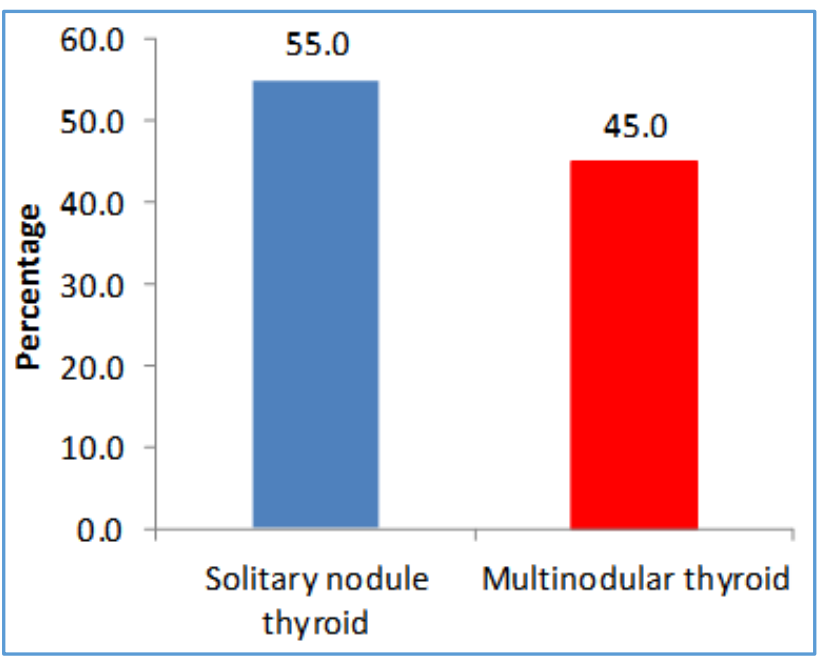

Graph 4. Percentage Distribution of the Sample, According to Diagnosis

In the study population, $55 \%$ that is 44 patients were diagnosed as SNT and $45 \%$ that is 36 patients were diagnosed as MNG.
5. Surgery

\begin{tabular}{|c|c|c|}
\hline Surgery & Count & Percent \\
\hline Hemithyroidectomy & 34 & 42.5 \\
\hline Total thyroidectomy & 46 & 57.5 \\
\hline \multicolumn{2}{|c|}{ Table 5. Percentage Distribution } \\
of the Sample, According to Surgery \\
\hline
\end{tabular}

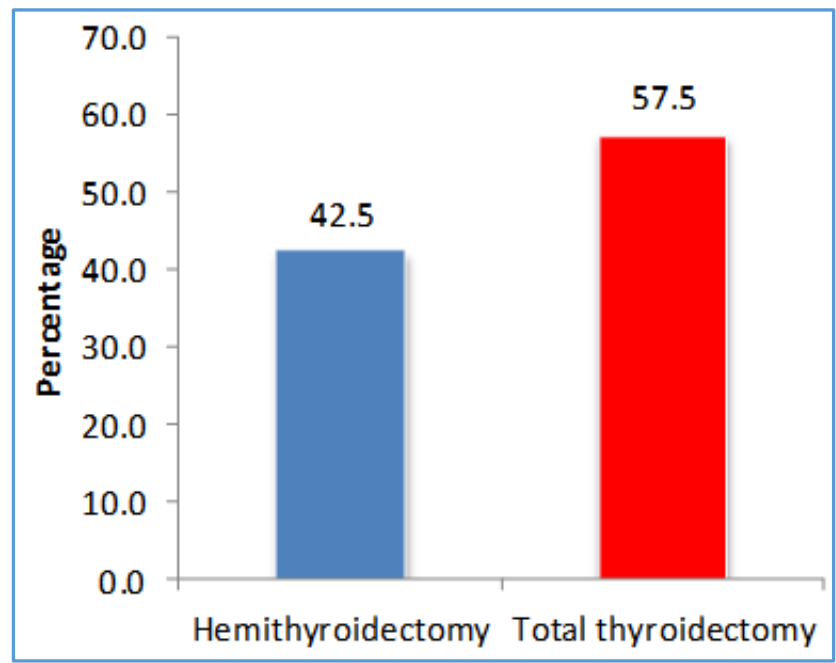

Graph 5. Percentage Distribution of the Sample, According to Surgery

In the study population $42.5 \%$ i.e. 34 patients underwent hemithyroidectomy and $57.5 \%$ i.e. 46 underwent total thyroidectomy.

6. Incision

\begin{tabular}{|c|c|c|}
\hline Incision & Count & Percent \\
\hline Lateral incision thyroidectomy & 40 & 50.0 \\
\hline Conventional thyroidectomy & 40 & 50.0 \\
\hline \multicolumn{2}{|c|}{ Table 6. Percentage Distribution } \\
of the Sample, According to Incision \\
\hline
\end{tabular}

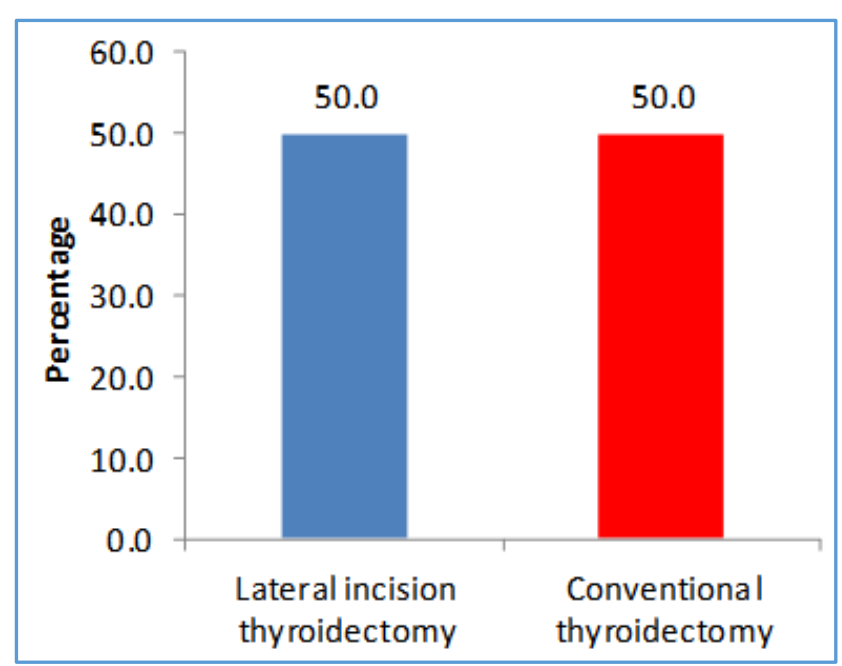

Graph 6. Percentage Distribution of the Sample, According to Incision 
7. Association of Complications with Incision

\begin{tabular}{|c|c|c|c|c|c|c|c|c|}
\hline \multirow{3}{*}{ Incision } & \multicolumn{6}{|c|}{ Hypocalcaemia } & \multirow{3}{*}{$\mathbf{Z}^{*}$} & \multirow{3}{*}{$\mathbf{P}$} \\
\hline & \multicolumn{2}{|c|}{ No } & \multicolumn{2}{|c|}{ Transient } & \multicolumn{2}{|c|}{ Permanent } & & \\
\hline & Count & Percent & Count & Percent & Count & Percent & & \\
\hline Lateral incision thyroidectomy & 26 & 65.0 & 11 & 27.5 & 3 & 7.5 & \multirow{2}{*}{0.74} & \multirow{2}{*}{0.459} \\
\hline Conventional thyroidectomy & 29 & 72.5 & 9 & 22.5 & 2 & 5.0 & & \\
\hline
\end{tabular}

*Mann-Whitney U Test

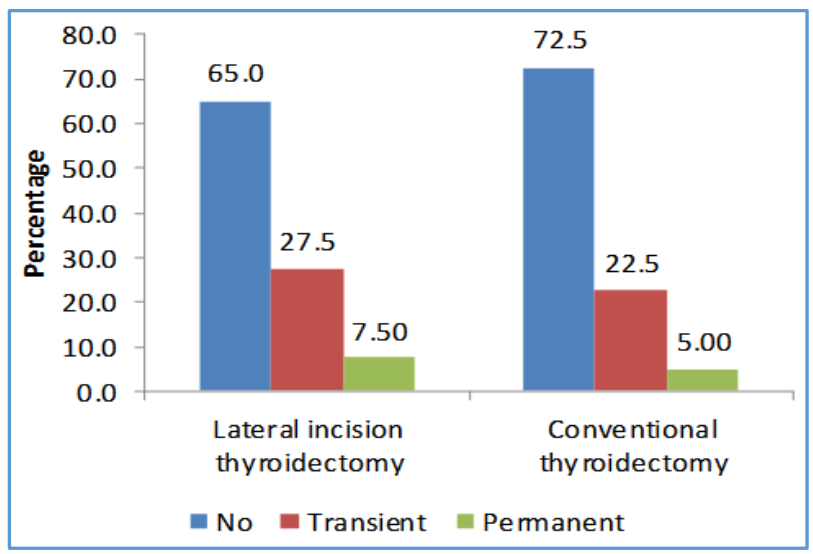

Occurrences of hypocalcaemia in both groups were analysed; $27.5 \%$ of patients in lateral incision group developed transient hypocalcaemia and $7.5 \%$ were permanent; $22.5 \%$ of patients in conventional thyroidectomy group developed transient hypocalcaemia and 5\% developed permanent hypocalcaemia. There is no statistically significant difference between the two groups with regard to occurrence of post-op hypocalcaemia [p value- 0.459 ].

Graph 7. Comparison of Incision based on Hypocalcaemia

8. Comparison of Incision based on Recurrent Laryngeal Nerve Palsy

\begin{tabular}{|c|c|c|c|c|c|c|c|c|}
\hline \multirow{3}{*}{ Incision } & \multicolumn{6}{|c|}{ Recurrent Laryngeal Nerve Palsy } & \multirow{3}{*}{$\mathbf{Z}^{*}$} & \multirow{3}{*}{$\mathbf{P}$} \\
\hline & \multicolumn{2}{|c|}{ No } & \multicolumn{2}{|c|}{ Apraxia } & \multicolumn{2}{|c|}{ Palsy } & & \\
\hline & Count & Percent & Count & Percent & Count & Percent & & \\
\hline $\begin{array}{l}\text { Lateral incision } \\
\text { thyroidectomy }\end{array}$ & 29 & 72.5 & 9 & 22.5 & 2 & 5.0 & \multirow{2}{*}{0.16} & \multirow{2}{*}{0.869} \\
\hline $\begin{array}{c}\text { Conventional } \\
\text { thyroidectomy }\end{array}$ & 28 & 70.0 & 11 & 27.5 & 1 & 2.5 & & \\
\hline
\end{tabular}

*Mann-Whitney U Test

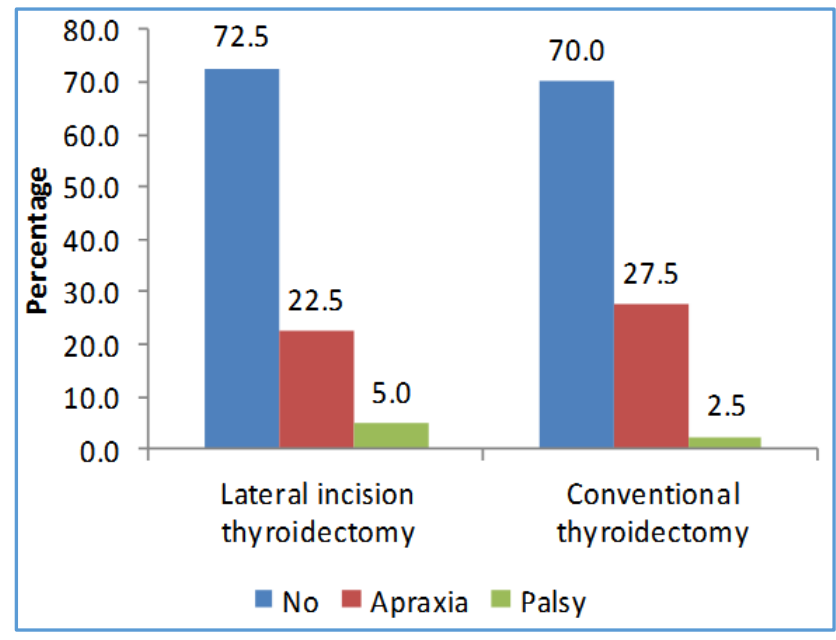

Graph 8. Comparison of Incision based on Recurrent Laryngeal Nerve Palsy
Occurrences of RLN palsy in both groups were analysed; $22.5 \%$ patients had RLN apraxia in lateral incision group and $5 \%$ had RLN palsy; $27.5 \%$ patients in conventional thyroidectomy developed RLN apraxia and $2.5 \%$ had palsy. There is no statistically significant difference between two groups with regard to occurrence of RLN injury [p value0.869].

\section{Comparison of OSAS based on Incision}

\begin{tabular}{|c|c|c|c|c|c|c|}
\hline \multirow{3}{*}{ OSAS } & \multicolumn{4}{|c|}{ Incision } & \multirow{3}{*}{$\mathbf{Z}^{*}$} & \multirow{3}{*}{$\mathbf{P}$} \\
\hline & \multicolumn{2}{|c|}{$\begin{array}{l}\text { Lateral Incision } \\
\text { Thyroidectomy }\end{array}$} & \multicolumn{2}{|c|}{$\begin{array}{l}\text { Conventional } \\
\text { Thyroidectomy }\end{array}$} & & \\
\hline & Count & Percent & Count & Percent & & \\
\hline$<15$ & 33 & 82.5 & 21 & 52.5 & & \\
\hline $15-34$ & 7 & 17.5 & 15 & 37.5 & 2.98 & $0.003 t$ \\
\hline $34-50$ & 0 & 0.0 & 4 & 10.0 & & \\
\hline
\end{tabular}

*Mann-Whitney U Test $†$ Significant at 0.01 level. 


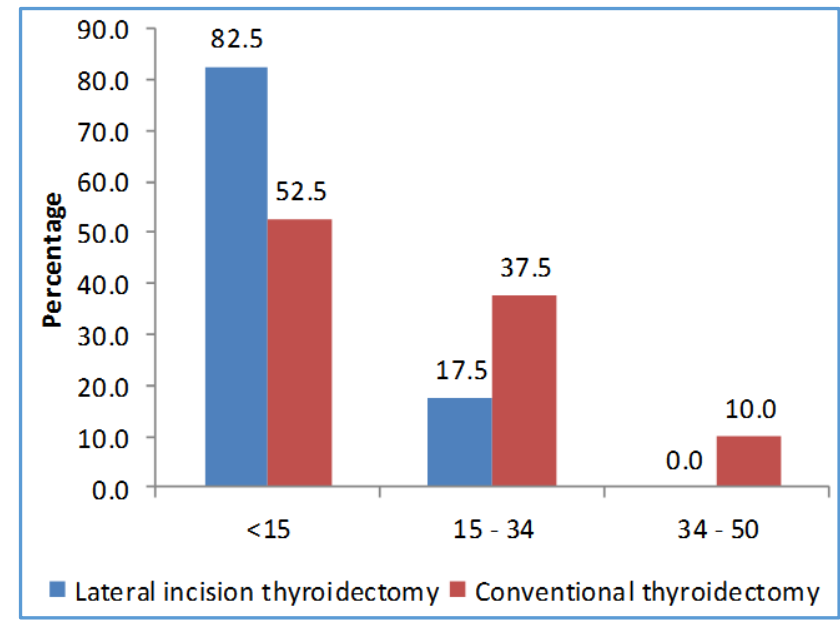

Graph 9. Comparison of OSAS based on Incision

There is statistically significant difference between the two groups with regards to the outcome of the scar in OSAS. The scar was significantly better in thyroidectomy done through lateral incision thyroidectomy [ $p$ value- 0.003 ].

\section{Comparison of PSAS based on Incision}

\begin{tabular}{|c|c|c|c|c|c|c|}
\hline \multirow{3}{*}{ PSAS } & \multicolumn{4}{|c|}{ Incision } & \multirow{3}{*}{$\mathbf{Z}^{*}$} & \multirow{3}{*}{$\mathbf{P}$} \\
\hline & \multicolumn{2}{|c|}{\begin{tabular}{|l|} 
Lateral Incision \\
Thyroidectomy
\end{tabular}} & \multicolumn{2}{|c|}{$\begin{array}{c}\text { Conventional } \\
\text { Thyroidectomy }\end{array}$} & & \\
\hline & Count & Percent & Count & Percent & & \\
\hline$<15$ & 35 & 87.5 & 19 & 47.5 & \multirow{3}{*}{3.87} & \multirow{3}{*}{$0.000 \dagger$} \\
\hline $15-39$ & 5 & 12.5 & 17 & 42.5 & & \\
\hline $40-50$ & 0 & 0.0 & 4 & 10.0 & & \\
\hline \multicolumn{7}{|c|}{ Table 10. Comparison of PSAS based on Incision } \\
\hline
\end{tabular}

*Mann-Whitney U Test †Significant at 0.01 level.

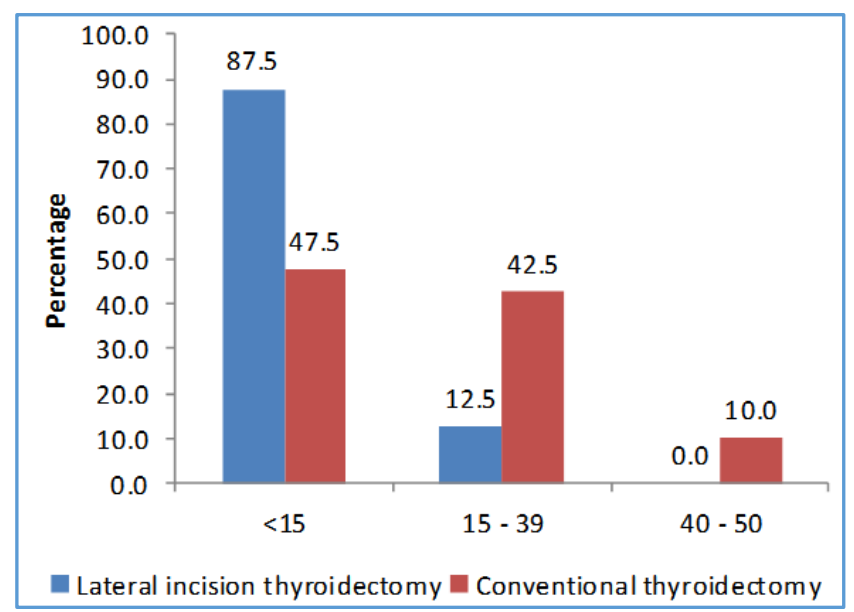

Graph 10. Comparison of PSAS based on Incision

There is statistically significant difference between the two groups with regards to the outcome of the scar in PSAS. The scar was significantly better in thyroidectomy done through lateral incision [p value- 0.000 ].

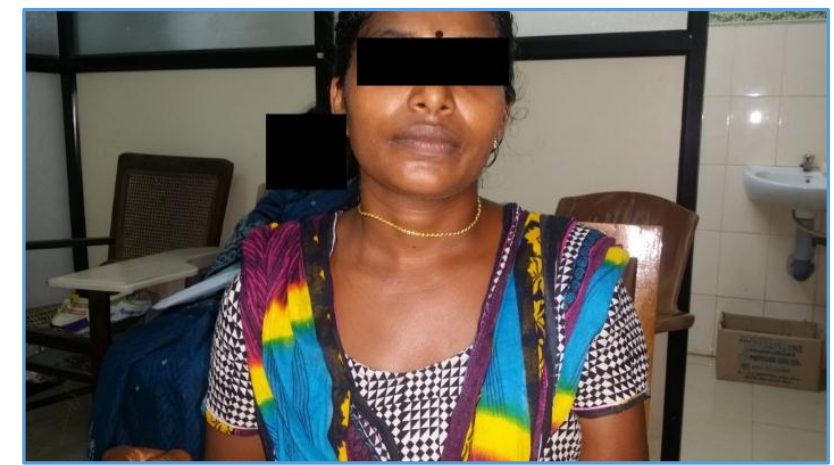

Figure 1

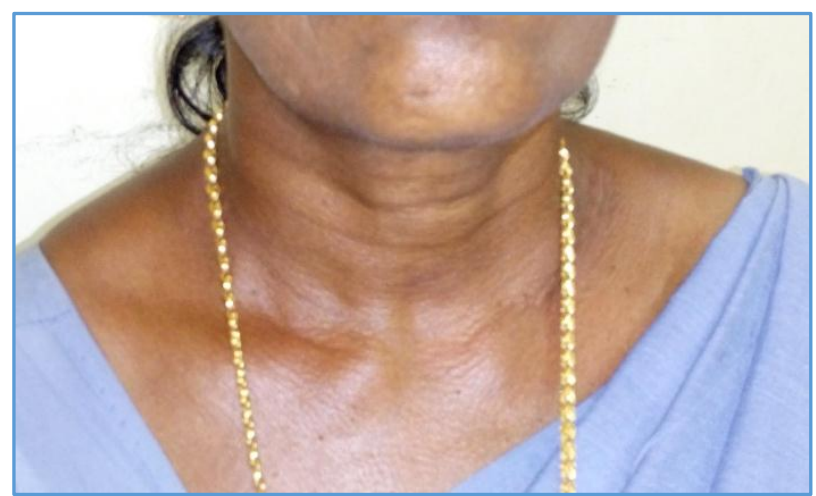

Figure 2

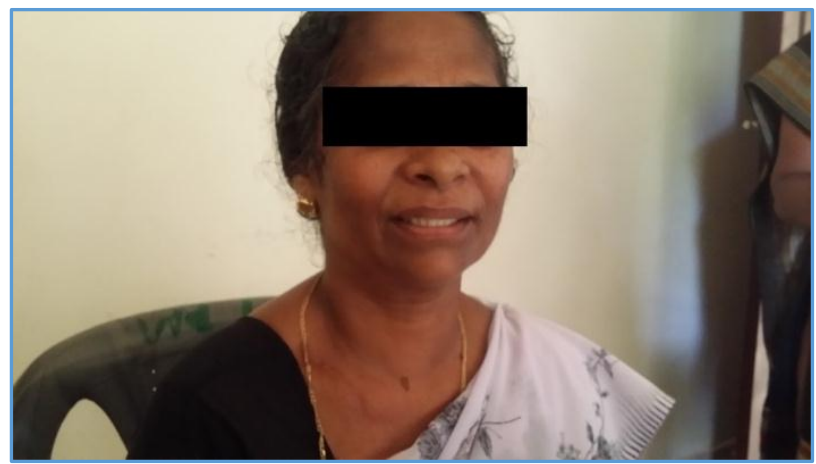

Figure 3

\section{DISCUSSION}

Age

Most of the patients in the study were in the age group 30 50 yrs., with that is $68.8 \%$ that is 30 patients in $40-50$ and 25 in 30 - 40 years' group.

\section{Sex}

In the study population, the percentage of female patients was $61 \%$ and the percentage of male was $19 \%$. In the study population 12 male patients included in age group $30-40$ and $50-60$, but in female patients $42.6 \%$ that is 26 patients included in age group 40 - 50. This finding was in concordance with the findings in the previous studies of horizontal lateral incision thyroidectomy by Thomas Varghese. ${ }^{1}$

\section{Diagnosis}

In the study population, $55 \%$ that is 44 patients were diagnosed as SNT and $45 \%$ that is 36 patients were diagnosed as MNG. 


\section{Surgery}

In the study population $42.5 \%$ i.e. 34 patients underwent hemithyroidectomy, $\quad 57.5 \%$ i.e. 46 underwent total thyroidectomy.

\section{Complications}

- Hypocalcaemia- Occurrences of hypocalcaemia ${ }^{2}$ in both groups were analysed; $27.5 \%$ of patients in lateral incision group developed transient hypocalcaemia and $7.5 \%$ were permanent; $22.5 \%$ of patients in conventional thyroidectomy group developed transient hypocalcaemia and $5 \%$ developed permanent hypocalcaemia. ${ }^{2}$ There is no statistically significant difference between the two groups with regard to occurrence of post-op hypocalcaemia [p value- 0.459 ]. In Thomas Varghese ${ }^{1}$ study of horizontal lateral incision thyroidectomy, parathyroid deficiency was reported in $10 / 283$ that is $0.035 \%$ only.

- Recurrent Laryngeal Nerve Palsy- Occurrences of RLN palsy ${ }^{3,4}$ in both groups were analysed; $22.5 \%$ patients had RLN apraxia in lateral incision group and $5 \%$ had RLN palsy; $27.5 \%$ patients in conventional thyroidectomy developed RLN apraxia and 2.5\% had palsy. There is no statistically significant difference between two groups with regard to occurrence of RLN injury [ $p$ value- 0.869]. There were no nerve injury reported in horizontal lateral incision thyroidectomy according to Thomas Varghese. ${ }^{1}$

- Cosmesis- Post-op scar was assessed based on the Patient's and Observer's point of view Observer scar assessment scale.5,6,7 There is statistically significant difference between the two groups with regards to the outcome of the scar in OSAS. The scar was significantly better in thyroidectomy done through lateral incision thyroidectomy [p value- 0.003 ].

This finding was in concordance with the previous studies of horizontal lateral incision thyroidectomy by Thomas Varghese, ${ }^{1}$ Zhi Giang Chen, ${ }^{8}$ Lei Wang, Tao Li et al and Terris et al, patient's scar assessment scale. There is statistically significant difference between the two groups with regards to the outcome of the scar in PSAS.5,6,7 The scar was significantly better in thyroidectomy done through lateral incision [p value- 0.000$]$.

This finding was in concordance with the previous studies of horizontal lateral incision thyroidectomy by Thomas Varghese ${ }^{1}$, Zhi Giang Chen, ${ }^{8}$ Lei Wang, Tao Li et al and Terris et al. The scar in lateral incision thyroidectomy was cosmetically far better compared to the conventional incision thyroidectomy.

\section{CONCLUSION}

Lateral or horizontal incision thyroidectomy is analogous and feasible alternative to conventional thyroidectomy in selected cases. The advantage of this technique was an enhanced aesthetic result. This technique is not recommended in huge thyroid, retrosternal thyroid, thyroiditis and malignancy, so it cannot be recommended as a standard therapy. Study on a large number of patients, preferably randomised doubleblinded studies with longer followup periods is recommended.

\section{ACKNOWLEDGEMENTS}

I am grateful to Dr. A. Abdul Latheef A, Professor and Head of the Department of General Surgery, T. D. Medical College, Alappuzha for his great help, expert guidance, suggestions, his valuable guidance, his constant help and support extended towards me.

I am sincerely grateful to Dr. I. J. Jinu, Assistant Professor, Department of General Surgery, Govt. T. D. Medical College, Alappuzha, advice and encouragement, he showed to me to get through this study.

I am thankful to the Principal and all the staff members of the Department of General Surgery, T. D. Medical College, Alappuzha for their valuable encouragement and support.

I thank all my co-PG's for their constructive criticism, constant help and encouragement during my study.

I also acknowledge my patients along with their attenders, who formed the base of my study and without their cooperation this work would not have been possible.

I also acknowledge Kerala University of Health Sciences for the support they have shown to me. In all those times when I needed a hand to seek support, I always found my family close by, let every opportunity to express my gratitude towards them be fruitful. Above all my deepest gratitude to the almighty for enabling me to complete the work.

\section{REFERENCES}

[1] Varghese T. 538. Horizontal lateral thyroidectomythomas' technique - a novel anatomical approach based on 3D interactive digital anatomy for superior results. Feasibility Study. Eur J Surg Oncol 2012;38(9):886-7.

[2] Noureldine SI, Genther DJ, Lopez M, et al. Early predictors of hypocalcemia after total thyroidectomy: an analysis of 304 patients using a short-stay monitoring protocol. JAMA Otolaryngol Head and Neck Surg 2014;140(11):1006-13.

[3] Zakaria HM, Al Awad NA, Al Kreedes AS, et al. Recurrent laryngeal nerve injury in thyroid surgery. Oman Med J 2011;26(1):34-8.

[4] Lo CY, Kwok KF, Yuen PW. A prospective evaluation of recurrent laryngeal nerve paralysis during thyroidectomy. Arch Surg 2000;135(2):204-7.

[5] Draaijers LJ, Tempelman FRH, Botman YAM, et al. The patient and observer scar assessment scale: a reliable and feasible tool for scar evaluation. Plast Reconstr Surg 2004;113(7):1960-5.

[6] Fearmonti RM, Bond JE, Erdmann D, et al. The modified Patient and Observer Scar Assessment Scale: a novel approach to defining pathologic and nonpathologic scarring. Plast Reconstr Surg 2011;127(1):242-7.

[7] van de Kar AL, Corion LUM, Smeulders MJC, et al. Reliable and feasible evaluation of linear scars by the Patient and Observer Scar Assessment Scale. Plast Reconstr Surg 2005;116(2):514-22.

[8] Chen ZQ, Wang L, Li T, et al. Supraclavicular lateral collar incision versus conventional approach for thyroidectomy: supplement for minimally invasive techniques with extended indications. J Laparoendosc Adv Surg Tech A 2011;21(1):45-50. 